\section{2cta 3 iologica Sibirica}

Journal of Biology

Founded in 2015
Altai State University

www.asu.ru

ISSN 2412-1908

Acta Biologica Sibirica, 2017, 3(4), 113-122

\title{
New data of chrysophycean stomatocysts from Lake Baikal
}

\author{
A.D. Firsova, A.Yu. Bessudova, Ye.V. Likhoshway \\ Limnological Institute of the Siberian Branch of the Russian Academy of Sciences, Irkutsk \\ adfir71@yandex.ru; annabessudova@mail.ru; likhoshway@mail.ru
}

The chrysophyte stomatocyst composition in phytoplankton of Lake Baikal in 2016 was studied using scanning electron microscopy. 20 morphotypes were detected, 8 of which were seen in the lake for the first time, and 5 were described as novel. For 3 morphotypes the species was determined based on the scale presence and structure.

Key words: chrysophycean stomatocysts; new morphotypes; Lake Baikal

\section{Новые данные о стоматоцистах хризофитовых из озера Байкал}

\author{
А.Д.Фирсова, А.Ю. Бессудова, Е.В. Лихошвай \\ Лимнологический институт Сибирского отделения \\ Российской Академии наук, Иркутск, Россия \\ adfir71@yandex.ru; annabessudova@mail.ru; likhoshway@mail.ru
}

\begin{abstract}
В результате исследований фитопланктона оз. Байкала в 2016 г. с помощью сканирующей электронной микроскопии определен состав стоматоцист хризофитовых, включающий 20 морфотипов. 8 морфотипов стоматоцист обнаружены в Байкале впервые, из них 5 описаны как новые. Для 3 по наличию чешуек и их строению удалось установить видовую принадлежность.
\end{abstract}

Ключевые слова: стоматоцисты хризофитовых, новые морфотипы, озеро Байкал

\section{Введение}

Хризофитовые - одна из ведущих групп фитопланктона, одной из особенностей которых является способность формировать кремнистые стоматоцисты (статоспоры), в определенные стадии своего развития или под воздействием изменений окружающей среды (Duff, et al., 1995; Voloshko, 2016). Они обитают, в основном, в пресных олиготрофных водоемах, предпочитая преимущественно чистые воды, поэтому служат индикаторами изменения качества воды, закисления, эвтрофикации озер (Cronberg, 1986; Kristiansen, 2005). Поскольку стоматоцисты прекрасно сохраняются в донных отложениях пресноводных водоемов, данные об их количестве и распределении определенных морфотипов по глубине осадка используются в палеореконструкциях (Duff et al., 1995; Kristiansen, 2005; Voloshko, 2016; Rondon, Catalan, 2017). Стоматоцисты имеют разную форму и 
поверхностную орнаментацию, описание которой проводят по определенному регламенту (Cronberg, Sandgren, 1986). Всего описано около 500 морфотипов стоматоцист, и в атласах-определителях они фигурируют под соответствующими номерами морфотипов (Duff, Zeeb, Smol, 1995; Wilkinson, Zeeb, Smol, 2001: Pla, 2001), так как большинство из них не соотнесено с конкретными видами определить видовую принадлежность стоматоцист возможно в двух случаях: (1) если удается в природе или при культивировании определенного вида наблюдать формирование стоматоцист, и (2) если в исследуемых препаратах природных образцов попадаются стоматоцисты, частично покрытые кремнеземными чешуйками, по которым в последнее время, используя методы электронной микроскопии, проводится идентификацию видов чешуйчатых хризофитовых (Škaloud et al., 2012; Škaloud et al., 2013; Scoble, Cavalier-Smith, 2014). В большинстве случаев исследователи присваивают обнаруженным и описанным стоматоцистам номера по системе, принятой международной группой по исследованию стоматоцист (ISWG) (Cronberg, Sandgren, 1986).

В Байкале стоматоцисты впервые были обнаружены в поверхностных осадках озера и в водах Иркутского водохранилища (Vorobyova et al., 1996), авторами было описано 7 стоматоцист. В дальнейшем с использованием сканирующей электронной микроскопии было описано 92 морфотипа ископаемых стоматоцист из голоценовых и верхнеплейстоценовых донных отложений Байкала и 35 - из фитопланктона (Firsova, Likhoshway, 2006). Исследована сезонная динамика формирования байкальских стоматоцист (Firsova et al., 2008). В настоящей работе мы приводим данные о новых стоматоцистах хризофитовых, обнаруженных в результате исследований фитопланктона 2016 г.

\section{Материалы и методы}

Исследованы пробы фитопланктона, отобранные в мае-июне и сентябре 2016 г. на 25 станциях озера Байкал с глубины 0-25 м (рис. 1, табл. 1). Для определения хризофитовых и их стоматоцист одновременно с батометрическими пробами осуществляли отбор образцов объемом 10-15 мл на фильтры Whatman диметром 13 мм и с диаметром пор 1 мкм, высушивали при комнатной температуре, напыляли золотом и исследовали с помощью сканирующих электронных микроскопов Philips SEM 525M и Quanta 200 FEI.

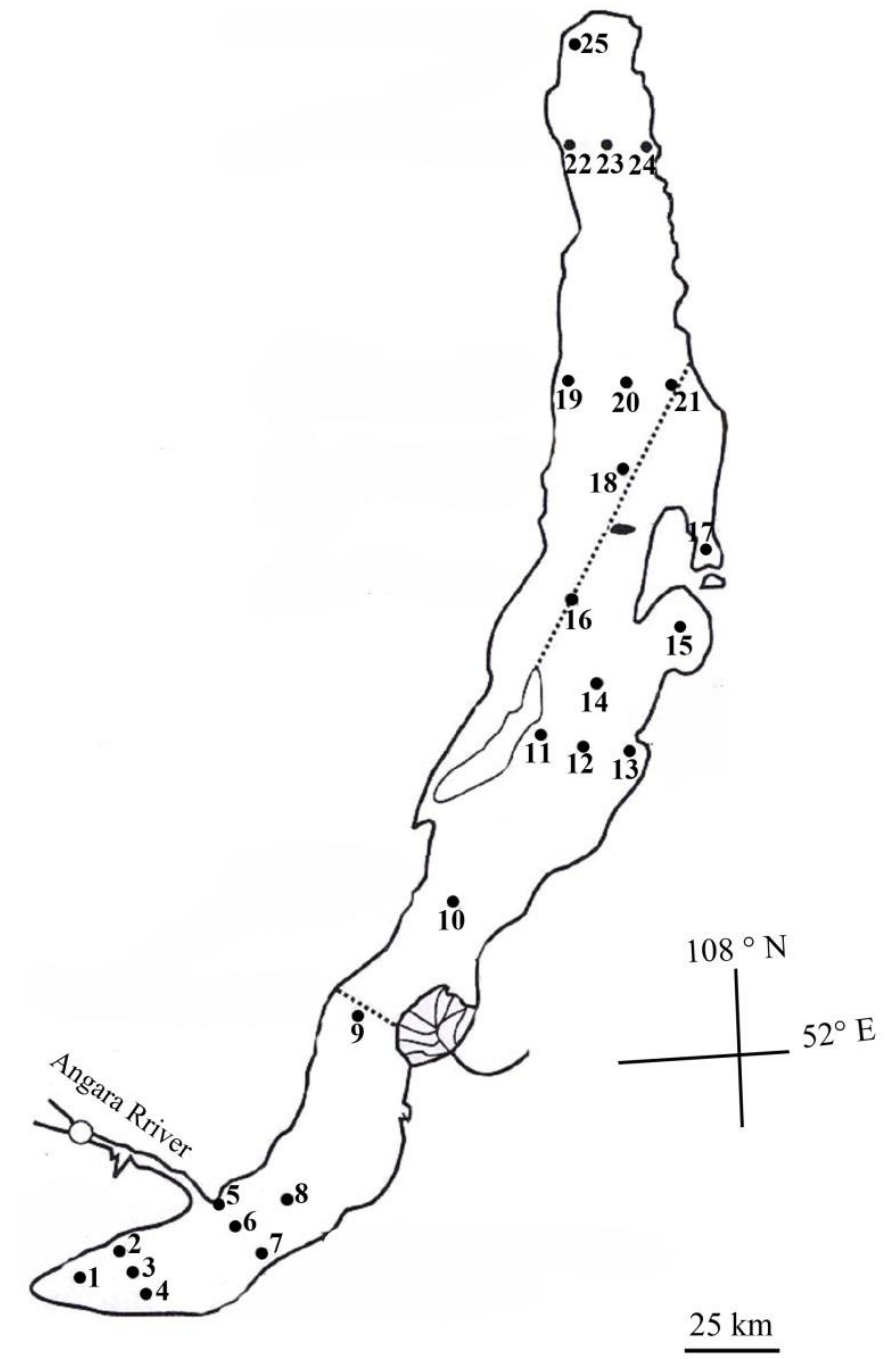

Рис. 1. Карта-схема станций отбора проб. Пунктирной линией обозначены границы районов: Южный, Средний и Северный Байкал 
Firsova, A.D. et al. (2017). New data of chrysophycean... Acta Biologica Sibirica, 2017, 3(4), 113-122

Таблица 1. Станции отбора проб (намера станций соответствуют приведенным на рис.1

\begin{tabular}{|c|c|c|c|}
\hline № & Координаты & Район & Название станции \\
\hline 1. & $51^{\circ} 40,578 \mathrm{~N}, 103^{\circ} 52,309 \mathrm{E}$ & \multirow{12}{*}{$\begin{array}{l}\text { Южный } \\
\text { Байкал }\end{array}$} & 15 км от Култука \\
\hline 2. & $51^{\circ} 45,546 \mathrm{~N}, 104^{\circ} 13,222 \mathrm{E}$ & & 3 км от Маритуя \\
\hline 3. & $51^{\circ} 38,710 \mathrm{~N}, 104^{\circ} 13,715 \mathrm{E}$ & & Маритуй-Солзан \\
\hline 4. & $51^{\circ} 31,428 \mathrm{~N}, 104^{\circ} 14,417 \mathrm{E}$ & & 3 км от Солзана \\
\hline 5. & $51^{\circ} 49,033 \mathrm{~N}, 104^{\circ} 54,616 \mathrm{E}$ & & З км от Листвянки \\
\hline 6. & $51^{\circ} 42,262 \mathrm{~N}, 105^{\circ} 00,720 \mathrm{E}$ & & Листвянка-Танхой \\
\hline 7. & $51^{\circ} 35,440 \mathrm{~N}, 105^{\circ} 06,968 \mathrm{E}$ & & 3 км от Танхоя \\
\hline 8. & $51^{\circ} 46,731 \mathrm{~N}, 105^{\circ} 22,528 \mathrm{E}$ & & Кадильный-Мишиха \\
\hline 9. & $52^{\circ} 20,722 \mathrm{~N}, 106^{\circ} 03,870 \mathrm{E}$ & & Харауз-Красный Яр \\
\hline 10. & $52^{\circ} 39,590 \mathrm{~N}, 106^{\circ} 50,978 \mathrm{E}$ & & Анга-Сухая \\
\hline 11. & $53^{\circ} 02,955 \mathrm{~N}, 107^{\circ} 25,657 \mathrm{E}$ & & 3 км от Ухана \\
\hline 12. & $52^{\circ} 53,630 \mathrm{~N}, 107^{\circ} 31,001 \mathrm{E}$ & & Ухан-Тонкий \\
\hline 13. & $52^{\circ} 44,618 \mathrm{~N}, 107^{\circ} 38,801 \mathrm{E}$ & \multirow{8}{*}{$\begin{array}{l}\text { Средний } \\
\text { Байкал }\end{array}$} & 3 км от Тонкого \\
\hline 14. & $53^{\circ} 21,278 \mathrm{~N}, 108^{\circ} 13,078 \mathrm{E}$ & & Хобой-Крестовый \\
\hline 15. & $53^{\circ} 27,245 \mathrm{~N}, 108^{\circ} 44,387 \mathrm{E}$ & & Баргузинский залив \\
\hline 16. & $53^{\circ} 38,063 \mathrm{~N}, 108^{\circ} 07,495 \mathrm{E}$ & & Академический хребет \\
\hline 17. & $53^{\circ} 42,564 \mathrm{~N}, 109^{\circ} 06,384 \mathrm{E}$ & & Чивыркуйский залив (глуб. 5 м) \\
\hline 18. & $54^{\circ} 16,860 \mathrm{~N}, 108^{\circ} 44,473 \mathrm{E}$ & & Заворотный-Сосновка \\
\hline 19. & $54^{\circ} 31,829 \mathrm{~N}, 108^{\circ} 42,310 \mathrm{E}$ & & 3 км от Елохина \\
\hline 20. & $54^{\circ} 27,052 \mathrm{~N}, 109^{\circ} 04,164 \mathrm{E}$ & & м. Елохин-Давша \\
\hline 21. & $54^{\circ} 22,754 \mathrm{~N}, 109^{\circ} 25,314 \mathrm{E}$ & \multirow{5}{*}{$\begin{array}{l}\text { Северный } \\
\text { Байкал }\end{array}$} & 3 км от Давши \\
\hline 22. & $55^{\circ} 20,966 \mathrm{~N}, 109^{\circ} 14,635 \mathrm{E}$ & & 3 км от Байкальска \\
\hline 23. & $55^{\circ} 19,487 \mathrm{~N}, 109^{\circ} 28,707 \mathrm{E}$ & & с. Байкальское-Турали \\
\hline 24. & $55^{\circ} 17,537 \mathrm{~N}, 109^{\circ} 42,947 \mathrm{E}$ & & 3 км от Турали \\
\hline 25. & $55^{\circ} 42,876 \mathrm{~N}, 109^{\circ} 36,573 \mathrm{E}$ & & 7 км от Нижнеангарска \\
\hline
\end{tabular}

\section{Результаты и их обсуждение}

В результате анализа сезонных проб фитопланктона 2016 г. отмечено, что общее количество стоматоцист максимально в осенних пробах, как и в предыдущие годы исследований (Firsova et al., 2008). Эти наблюдения свидетельствуют, что большинство таксонов хризофитовых заканчивают свой жизненный цикл осенью, а развиваются летом.

В фитопланктоне озера Байкал в сентябре 2016 г. обнаружено 20 различных морфотипов стоматоцист (рис. 2-4), из них 8 обнаружены в Байкале впервые. Ниже приводится их описание.

Стоматоциста 156 Zeeb \& Smol, 1993 (рис. 2a)

Биологическая принадлежность. До настоящего времени была неизвестна. При исследовании проб на этих цистах часто обнаруживались чешуйки и щетинки Chrysosphaerella coronacircumspina Wjuek \& Kristiansen (pис. 3а, d), и мы относим данный морфотип- к этому виду.

Номер изображения. 14927 cysta_002_004.

Локализация. Оз. Байкал, ст. № 1, 4, 5, 6, 10, 19, 20, 23, 25.

сэм-описание. Стоматоциста сферической формы, диаметром 9,5-11 мкм. Пора (диаметр 0,7 мкм) окружена широким плоским аннулусом (диаметр 2,5 мкм) и валикообразным воротничком (высота 0,3-0,4 мкм). Соотношение диаметра поры к диаметру стоматоцисты 0,2. Поверхность стоматоцисты гладкая.

Ссылки. Chrysosphaerella coronacircumspina широко распространенный вид, встречается в Европе, Северной Америке, Австралии (Hällifors, Hällifors, 1988), в России обнаружен в Хантайском водохранилище, в оз. Капш (северо-запад России) (Safonova, Voloshko, 2013), в районе Ладожского озера (Волошко, Гаврилова, Громов, 2002) и в районе Нижнего Енисея (Бессудова и др., 2016). Для Байкала приводится впервые.

Стоматоциста 453 nov. Firsova \& Bessudova (рис. 2b) Описана впервые

Биологическая принадлежность. Неизвестна.

Номер изображения. 14927_002_006.

Локализация. Оз. Байкал, ст. № 10. 
сэм-описание. Стоматоциста сферической формы, диаметром 6-6,5 мкм. Поверхность стоматоцисты гладкая. Пора небольшая, вдавленная, диаметром 0,4-0,5 мкм, окружена широким, неровным аннулусом (3,2×1,6), неравномерно орнаментированным мелкими вмятинами различного диаметра, край валикообразный высотой 0,2-0,3 мкм.

Ссылки. Среди опубликованных стоматоцист такой морфотип не обнаружен.

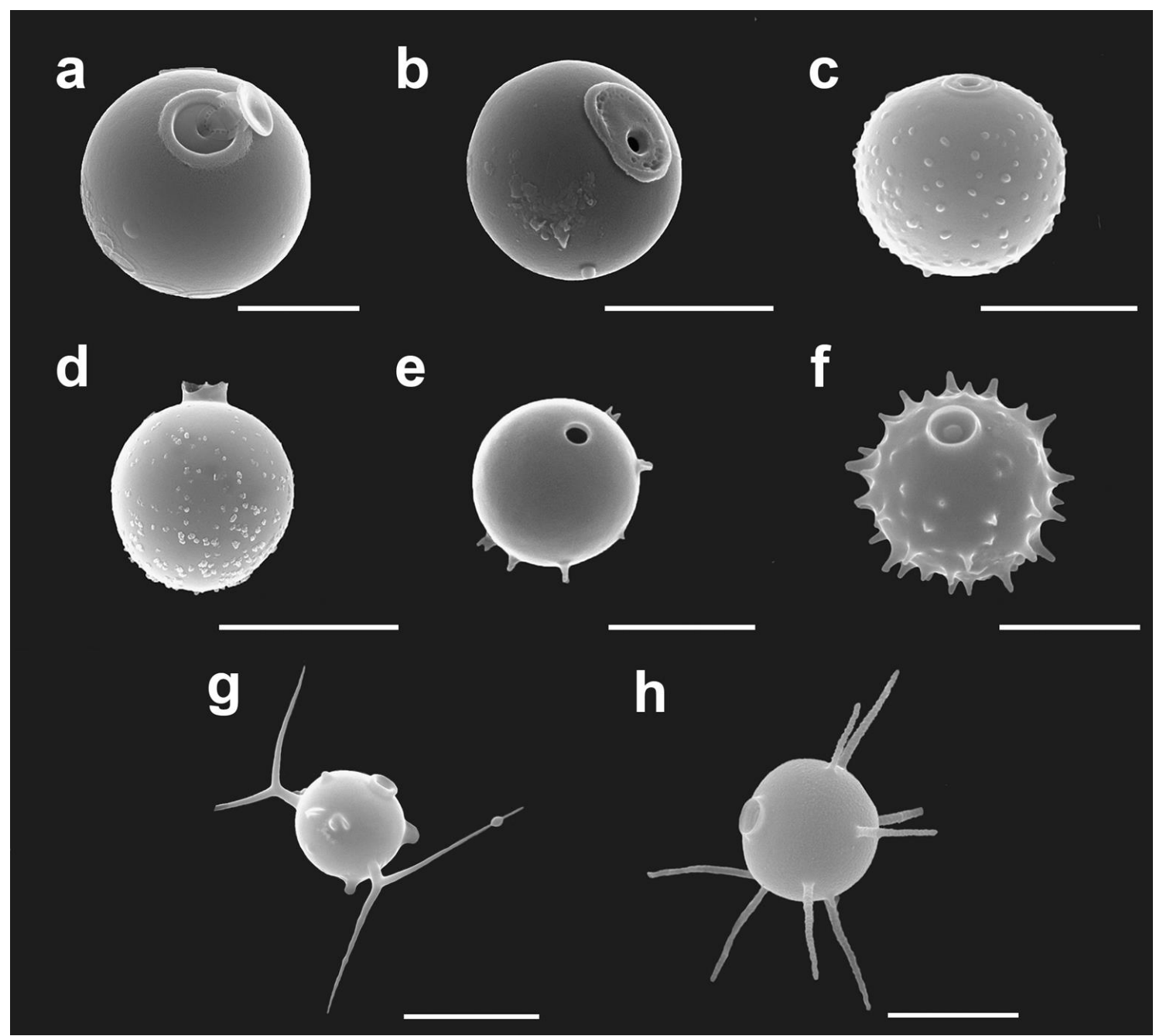

Рис. 2. Стоматоцисты, впервые обнаруженные в оз. Байкал:

a - Стоматоциста 156 Zeeb \& Smol, 1993; b - Стоматоциста 453 nov. Firsova \& Bessudova; c - Стоматоциста 452 nov. Firsova \& Bessudova; d - Стоматоциста 451 nov. Firsova \& Bessudova; e - Стоматоциста 319 Brown \& Smol, 2001; f Стоматоциста 450 nov. Firsova \& Bessudova; g - Стоматоциста 454 nov. Firsova \& Bessudova; $\mathrm{h}$ - Стоматоциста 262 Zeeb \& Smol, 1996. Масштаб: a, b, h - 5 мкм; c - 4 мкм; d, g - 10 мкм; e, f - 3 мкм

Стоматоциста 452 nov. Firsova \& Bessudova (рис. 2c). Описана впервые

Биологическая принадлежность. Неизвестна.

Номер изображения. 14929 сysta.

Локализация. Оз. Байкал, ст. № 2, 12.

сэм-описание. Мелкая сферическая стоматоциста, диаметром 5,5 мкм. Пора мелкая, диаметром 0,3-0,4 мкм, окруженная вздутым псевдоаннулусом, диаметром 0,6 мкм и валикообразным апексом (1,4 мкм, высота 0,1 мкм). Поверхность стоматоцисты покрыта мелкими бородавчатыми выростами сходными между собой по размеру (диаметр 0,2 мкм) и форме, на передней части расположение выростов немного реже.

Ссылки. Этот морфотип имеет некоторое сходство со Стоматоцистой S 167 Pla (Pla, 2001), но отличается более мелкими размерами и строением выростов, а также со Стоматоцистой 306 Firsova, 2006, отличаясь формой воротничка и количеством выростов.

Стоматоциста 451 nov. Firsova \& Bessudova (рис. 2d) Описана впервые

Биологическая принадлежность. Неизвестна.

Номер изображения: 14933 cysta.

Локализация. Оз. Байкал, ст. № 21.

Сэм-описание. Стоматоциста сферической или немного обратнояйцевидной формы, диаметром 10-10,7 мкм. Воротничок конический или обратноконический высотой 1,2 мкм, шириной 2,5 мкм. Поверхность 
шероховатая, неравномерно покрыта в экваториальной и задней части стоматоцисты мелкими бородавчатыми выростами различной формы и размера (более 100).

Ссылка. Байкальский морфотип сходен со Стоматоцистами 29 Rybak et al. и 79 Duff \& Smol, 1991, отличается по размеру, форме самой стоматоцисты и форме воротничка.
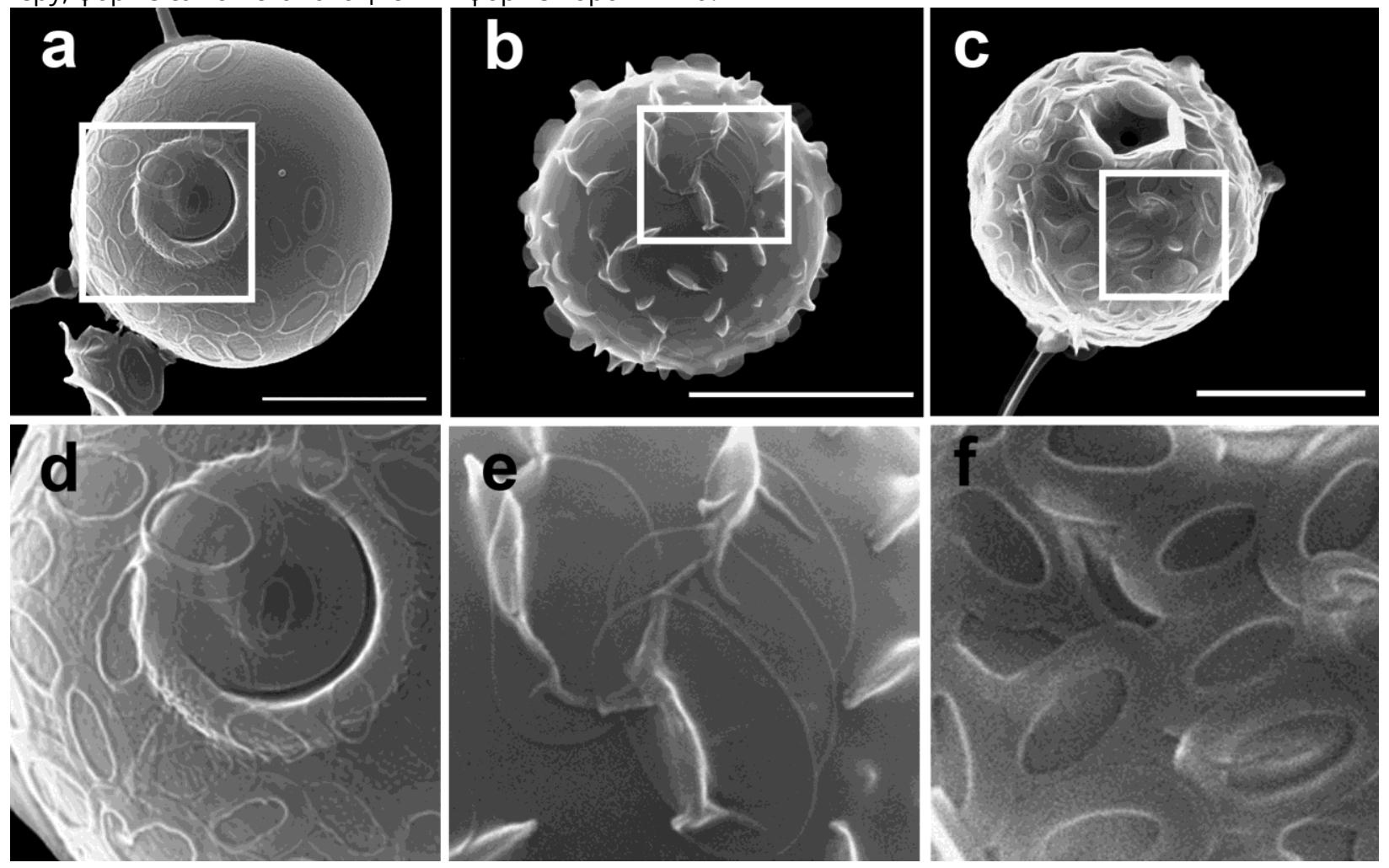

Рис. 3. Кремнистые чешуйки на поверхности стоматоцист:

a - Стоматоциста 156 Zeeb \& Smol, 1993; b - Стоматоциста 302 Firsova, 2006; с - Стоматоциста 223 Firsova \& Likhjshway, 2006; d - чешуйки Chrysosphaerella coronacircumspina; е - чешуйки Spiniferomonas septispina; f - чешуйки S. trioralis.

Стоматоциста 319 Brown \& Smol, 2001 (рис. 2e)

Биологическая принадлежность. Неизвестна.

Номер изображения: 14927 cysta_002_003.

Локализация. Оз. Байкал, ст. № 10.

сэм-описание. Мелкая стоматоциста сферической формы (диаметр 3,5 мкм). Пора простая диаметром 0,4 мкм, окруженная очень маленьким заостренным апексом (0,1-0,2 мкм), напоминающим заостренный выступ вокруг поры. Поверхность гладкая, задняя и экваториальная сторона орнаментирована разрозненными, иногда сдвоенными, палочковидными или чуть заостренными шипами (10-15, высота 0,3-0,4 мкм).

Ссылки. Этот морфотип сходен со Стоматоцистой 4, Duff \& Smol, 1988 (Duff et al., 1995), но отличаются количеством и расположением шипов,отсутствием выступающего апекса, а также более мелкими размерами. Морфотипы такого вида встречались в озерах северо-восточных территорий Канады, в осадочном керне глубиной 0-0,5 см, а также в водоемах центральной Европы. Отмечены при относительно высокой концентрации азота, при температуре 15,7-20,8 Co (Wilkinson, Zeeb, Smol, 2001). Для Байкала приводится впервые.

Стоматоциста 450 nov. Firsova \& Bessudova (рис. 2f) Описана впервые

Биологическая принадлежность. Неизвестна.

Номер изображения. 14937 сysta_0031.

Локализация. Озеро Байкал, ст. № 3, 19.

сэм-описание. Мелкая стоматоциста сферической формы, диаметром 4 мкм. Воротничок простой, цилиндрический, диаметром 1 мкм, с тонким апексом. Пора вдавленная, диаметром 0,4 мкм. Вся поверхность стоматоцисты покрыта шиповатыми выростами высотой от 0,2 до 0,7 мкм с простыми основаниями (70-80). Ближе к воротничку выросты короче.

Ссылка. Сходна со Стоматоцистами 158, 159 Firsova \& Likhoshway, 2006 (Firsova, Likhoshway, 2006), отличаясь формой и расположением шипов, а также со Стоматоцистами 318 Brown \& Smol, 1997 (Wilkinson et al., 2001$)$ и 170 Zeeb \& Smol, 1993 (Duff et al., 1995) но отличается формой воротничка и формой выростов.

Стоматоциста 454 nov. Firsova \& Bessudova (рис. 2g). Описана впервые

Биологическая принадлежность. Неизвестна. 
Firsova, A.D. et al. (2017). New data of chrysophycean.... Acta Biologica Sibirica, 2017, 3(4), 113-122

Номер изображения. 14939 cysta_0032.

Локализация. Оз. Байкал, ст. № 23.

Сэм-описание. Шарообразная стоматоциста диаметром 8,2 мкм. Воротничок цилиндрический, шириной 2 мкм, высотой 0,5 мкм. Циста имеет 2 или более длинных раздвоенных шипа, их длина до развилки 1,7 мкм, после - 9,9-11,9 мкм. Также покрыта короткими высокими гребнями и мелкими шипами (около 10), высотой 0,8-1,3 мкм.

Ссылки. Сходна со Стоматоцистой 221 Duff \& Smol, 1994 (Duff et al., 1995), но отличается отсутствием гребней, высотой и формой воротничка.

Стоматоциста 262 Zeeb \& Smol, 1996, (рис. 2h)

Биологическая принадлежность. Неизвестна.

Номер изображения: 14937 cysta_002.

Локализация. Оз. Байкал, ст. № 24, 25.

сэм-описание. Стоматоциста сферической формы, диаметром 5,5 мкм. Воротничок конический, невысокий, 0,3 мкм, диаметром 1,5 мкм. Задняя и экваториальная часть стоматоцисты орнаментирована длинными, 2,5-5 мкм, шипами (10-15).

Ссылки. Этот морфотип имеет сходство со Стоматоцистой 153 Firsova \& Likhoshway, 2006, но отличается более мелкими размерами, а также длиной и формой шипов. Такие морфотипы обильно встречались в поверхностных осадках оз. Боннилита (Коста Рика) (Wilkinson, Zeeb, Smol, 2001). Для Байкала приводится впервые.

12 морфотипов стоматоцист были отмечены в Байкале ранее. Для двух из них в результате настоящего исследования удалось определить видовую принадлежность. Ниже приводится их описание.

Стоматоциста 42 Duff \& Smol, 1991 (рис. 4a)

Биологическая принадлежность. Эта стоматоциста может быть продуцирована видами Synura petersenii Korshikov или Chrysosphaerella longispina Lauterborn emend. Nicholls (Duff, Zeeb \& Smol, 1995).

Номер изображения. 14810 сysta_001.

Локализация. Оз. Байкал, ст. № 2.

Сэм-описание. Стоматоциста сферическая или немного приплюснутая диаметром 12-12,8 мкм. Воротничок отсутствует. Поверхность стоматоцисты гладкая или микротекстурированная, без инкрустаций. Пора вдавленная (диаметр 0,6 мкм), окруженная плоским аннулусом (ширина аннулуса 0,3 мкм).

Ссылка. Эта морфотип имеет сходство со Стоматоцистами 120,15 и 150, Duff \& Smol (Duff et al., 1995), a также со Стоматоцистами 129 и 128 Firsova \& Likhoshway, 2006, отличаясь чуть более крупными размерами.

Стоматоциста 189 Firsova \& Likhoshway, 2006 (рис. 4b)

Биологическая принадлежность. Неизвестна.

Номер изображения: 14917 cysta_001.

Локализация. Оз. Байкал, ст. № 2, 25.

сэм-описание. Стоматоциста сферической формы, диаметром 9,1-9,3 мкм. Пора крупная простая, диаметром 1,3 мкм, вокруг небольшой плоский аннулус шириной 0,3 мкм. Стоматоциста неравномерно орнаментирована мелкими и крупными иногда двух-трехголовчатыми бородавчатыми (в диаметре 0,2-0,7 мкм) и невысокими шиповатыми выростами (высотой 0,2-0,7 мкм), широкими у основания (около 60).

Ссылка. Этот морфотип напоминает Стоматоцисту 155 Firsova, 2006, но отличается наличием аннулуса, а также строением выростов.

Стоматоциста 347 Firsova, 2006 (рис. 4c)

Биологическая принадлежность. Неизвестна.

Номер изображения: 14934 суsta 1.

Локализация. Оз. Байкал, ст. № 2, 16, 18, 19, 21, 20.

сэм-описание. Стоматоциста сферической формы, диаметром 10,5 мкм. Пора вдавленная, диаметром 1 мкм, окруженная утолщенным апексом, диаметром 1,7 мкм. Экваториальная и задняя часть стоматоцисты покрыта мелкими бородавчатыми и шиповатыми выростами. У экватора выросты мелкие, сливающиеся в сетчатый узор. На передней части, несколько отдельных бородавчатых выростов крупнее (около 10), 0,4-0,5 мкм в диаметре.

Ссылка. Такие стоматоцисты встречались в планктоне Южного Байкала (Firsova, Likhoshway, 2006), немного отличаясь формой поры и орнаментацией.

Стоматоциста 201 Firsova, 2006 (рис. 4d)

Биологическая принадлежность. Неизвестна.

Номер изображения: 14927 cysta_002_007.

Локализация. Оз. Байкал, ст. № 3, 10.

сэм-описание. Стоматоциста сферической формы, диаметром 10-10,6 мкм. Воротничка нет. Пора диаметром 0,9 мкм, без анулуса. Орнаментирована длинным, тонким, непрерывным гребнем, чуть ниже экватора 
(высотой 0,5-3,4 мкм). Задняя часть стоматоцисты покрыта округлыми неровными вмятинами (около 40) различного диаметра (0,4-2 мкм).

Ссылки. Сходна со Стоматоцистами 342 Firsova, 2006 и 344 Firsova, 2006, а также со стоматоцистами 202 Firsova \& Likhoshway, 2006 и 206 Firsova \& Likhoshway, 2006, отличаясь формой и величиной вмятин. Эти морфотипы и раньше встречались в планктоне Южного Байкала и наибольшего развития достигали в августе (Firsova et al., 2008), в целом, совпадает с ранее приведенным диагнозом.

Стоматоциста 301 Firsova \& Likhoshway, 2006 (рис. 4е)

Биологическая принадлежность. Неизвестна.

Номер изображения. 14916 cysta_002.

Локализация. Оз. Байкал, ст. № 1, 2, 3.

сэМ-описание. Мелкая стоматоциста сферической формы (диаметр 3,3 мкм). Воротничок цилиндрический или немного обратноконический (диаметр 1,2 мкм; высота 0,5 мкм), с острым апексом. Вся поверхность цисты орнаментирована (около 20) различными по форме и размерам длинными гребнями (высота 0,2-0,5 мкм; длина 0,5-2 мкм). Основание гребней простое. Пора цилиндрическая (диаметр 0,4 мкм) окруженная плоским аннулусом (ширина 0,5 мкм).

Ссылка. Это стоматоцисты и ранее встречались в Южном Байкале, но немного отличаются формой воротничка.

Стоматоциста 223 Firsova \& Likhoshway, 2006 (рис. 4f)

Биологическая принадлежность. Этот морфотип принадлежит виду Spiniferomonas trioralis Takahashi (рис. 3c, f).

Номер изображения: 14916_013.

Локализация. Оз. Байкал, ст. № 1, 2, 3, 4, 8, 6, 10, 12, 23.

Сэм-описание. Стоматоциста сферической формы, диаметром от 8 до 9,5 мкм. Диаметр (2,5-3,5 мкм) и высота (0,2-0,8 мкм) воротничка значительно варьируют. Соответственно варьирует по размеру и аннулус вокруг поры. Пора диаметром 0,5-0,7 мкм. Количество гребней варьирует от 80 до 115, длина гребней также варьирует от 0,5 до 3 мкм.

Ссылка. Морфотип сходен со Стоматоцистой 111, Zeeb, 1990 (Duff et al., 1995). Spiniferomonas trioralis широко распространенный вид, для которого свойственен широкий диапазон состояний окружающей среды. Эти морфотипы и раньше встречались в Южном Байкале, наибольшего обилия достигали в августе (Firsova et al., 2008).

Стоматоциста 302 Firsova, 2006 (рис. 4g)

Биологическая принадлежность. В настоящем исследовании неоднократно встречались эти морфотипы, покрытые чешуйками Spiniferomonas septispina Nicholls (рис. 3b, е), поэтому мы относим этот морфотип к S. septispina.

Номер изображения: 14943 cysta.

Локализация. Оз. Байкал, ст. № 1, 2, 3, 4, 14, 25.

сэм-описание. Стоматоциста сферической формы, диаметром 6,5 мкм. Вся поверхность неравномерно покрыта короткими, тонкими, словно лепестки, гребнями, расширяющимися по апикальному краю (около 100), высотой 0,4-0,5 мкм, длиной 0,4-1,5 мкм. Встречаются мелкие шиповатые выросты.

Ссылка. Этот морфотип и ранее встречался в планктоне Южного Байкала (Firsova \& Likhjshway, 2006).

Стоматоциста 317 Firsova, 2006 (рис. 4h)

Биологическая принадлежность. Неизвестна.

Номер изображения: 14937 cysta.

Локализация. Оз. Байкал, ст. 1, 2, 3, 4, 24, 25.

сэм-описание. Стоматоциста небольшая, шарообразной или чуть приплюснутой формы, диаметром 4,7 мкм. Пора мелкая, диаметром 0,4 мкм, окруженная вдавленным аннулусом. Воротничок обратноконический, невысокий, диаметром 1,6 мкм. Задняя и экваториальная часть стоматоцисты покрыта шипами различной высоты (0,2-1,2 мкм) с расширенным основанием.

Ссылка. Эти морфотипы и раньше встречались в Южном Байкале и наибольшего развития достигали в августе (Firsova et al., 2008), обнаруженные в данном исследовании экземпляры немного отличаются от описанного диагноза более мелкими размерами.

Стоматоцист 338 Firsova, 2006 (рис. 4i)

Биологическая принадлежность. Неизвестна.

Номер изображения: 14916 cysta_006.

Локализация. Оз. Байкал, ст. № 1,2, 10, 18. 
Сэм-описание. Стоматоциста сферической формы, диаметром 5,5-6 мкм. Пора вдавленная, окруженная небольшим плоским аннулусом (диаметр 0,3 мкм) и невысоким воротничком (диаметр 1,5 мкм, высота 0,3 мкм), с плоским апексом, шириной 0,3 мкм. Экваториальная и задняя часть стоматоцисты неравномерно покрыты палочковидными и заостренными шипами (45-60), иногда широкими у основания, различной высоты от 0,2 до 1,5 мкм. Мелкие шипы к передней части переходят в бородавчатые выросты. Больше половины шипов имеют раздвоенный и тройчатый конец. Иногда основания шипов уплощаются, образуя небольшие гребни.

Ссылки. Такие стоматоцисты встречались в Южном Байкале и ранее, достигая наибольшего развития в августе (Firsova et al., 2008). Этот морфотип имеет сходство со Стоматоцистами 180 Firsova \& Likhoshway, 2006 и 156 Firsova \& Likhoshway, 2006, обнаруженным в осадках Байкала в районе Академического хребта (Firsova, Likhoshway, 2006), но отличается плотностью и формой шипов, а также величиной самой стоматоцисты.

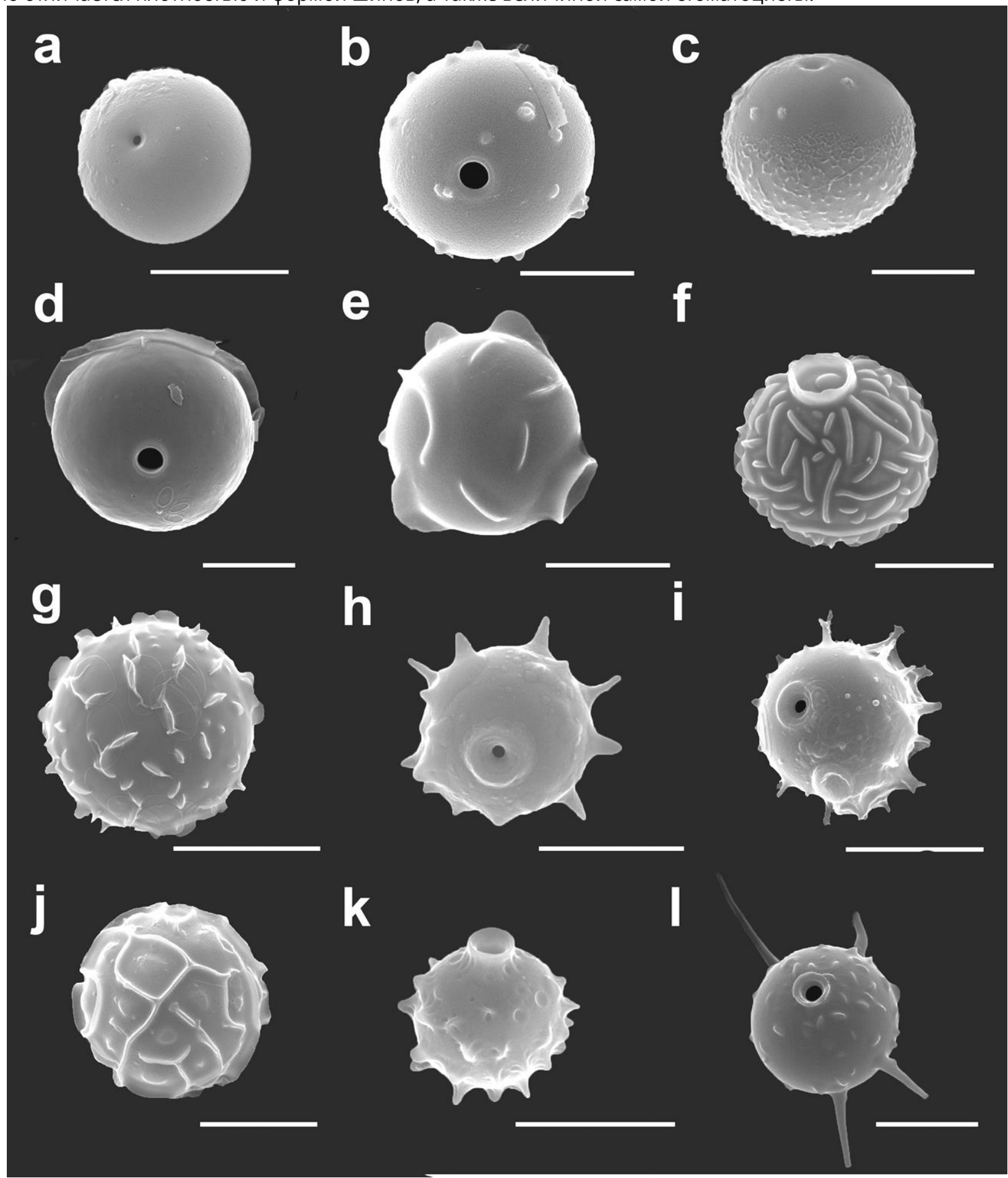

Рис. 4. Стоматоцисты, ранее отмеченные в оз. Байкал:

a - Стоматоциста 42 Duff \& Smol, 1991; b - Стоматоциста 189 Firsova \& Likhoshway, 2006; с - Стоматоциста 347 Firsova, 2006; d - Стоматоциста 201 Firsova, 2006; е - Стоматоциста 301 Firsova \& Likhoshway, 2006; f - Стоматоциста

223 Firsova \& Likhjshway, 2006; g - Стоматоциста 302 Firsova, 2006; h - Стоматоциста 317 Firsova, 2006; i Стоматоциста 338 Firsova, 2006; j - Стоматоциста 225 Firsova \& Likhoshway, 2006; k - Стоматоциста 307 Firsova, 2006; I - Стоматоциста 314 Firsova \& Likhoshway, 2006. Масштаб: e - 2 мкм; h, k - 4 мкм; b, c, d, f, g, j, I - 5 мкм; a - 10 мкм. 
Firsova, A.D. et al. (2017). New data of chrysophycean.... Acta Biologica Sibirica, 2017, 3(4), 113-122

Стоматоциста 225 Firsova \& Likhoshway, 2006 (рис. 4j)

Биологическая принадлежность. Неизвестна.

Номер изображения: 14923 суsta_006.

Локализация. Оз. Байкал, ст. № 6, 8.

Сэм-описание. Стоматоциста сферической формы, диаметром 8 мкм. Равномерно покрыта широкими ячейками (35-40), образованными непрерывными невысокими (0,6 мкм) гребнями. Внутри каждой ячейки неровный выступ диаметром 0,7-1 мкм.

Ссылка. Эта стоматоциста сходна со стоматоцистой 224 Firsova \& Likhoshway, 2006, отличаясь по величине ячеек. Ранее встречалась в осадках Байкала (Академический Хребет) (Firsova, Likhoshway, 2006), но данный экземпляр немного крупнее.

Стоматоциста 307 Firsova, 2006 (рис. 4k)

Биологическая принадлежность. Неизвестна.

Номер изображения: 14929 cysta_001.

Локализация. Оз. Байкал, ст. № 1, 2, 3, 4, 10, 12, 16, 24.

сэм-описание. Мелкая шарообразная стоматоциста, диаметром 3,6 мкм. Пора диаметром 0,3-0,4 мкм, окружена коническим или обратноконическим воротничком (диаметр 1,2 мкм; высота 0,5 мкм), орнаментированным продольными ребрами, не доходящими до края воротничка. На передней части стоматоцисты, вокруг воротничка, несколько (около 10) круглых вмятин диаметром 0,3-0,4 мкм. Экваториальная и задняя часть стоматоцисты орнаментирована короткими, высокими, закругленными гребнями с продольными ребрами (около 50).

Ссылки. Имеет сходство со Стоматоцистами 44 Rybak et al., 1991 (Rybak et al., 1991), 232 Duff \& Smol, 1994 (Duff et al., 1995), а также Стоматоцистой 352 Firsova, 2006 (Firsova, Likhoshway, 2006). Такие морфотипы и раньше встречались в Южном Байкале, наибольшего обилия достигали в октябре (Firsova et al., 2008). Обнаруженный экземпляр, в целом, совпадает с ранее приведенным описанием.

Стоматоциста 314 Firsova \& Likhoshway, 2006 (рис. 4l)

Биологическая принадлежность. Неизвестна.

Номер изображения. 14916 cysta_002.

Локализация. Оз. Байкал, ст. № 2, 3, 24.

сэм-описание. Стоматоциста сферической формы (диаметр 7,5 мкм). Воротничок в виде валика (диаметр 1,7 мкм; высота 0,3 мкм). Поверхность цисты орнаментирована (около 40) мелкими неровными гребнями (длина 0,60,8 мкм; высота 0,3-0,4 мкм). На задней части стоматоцисты расположены четыре длинных неровных шипа (длина шипов 1,4-7 мкм). Основания шипов орнаментированы бородавчатыми выростами. Пора цилиндрическая (диаметр 0,9 мкм) без аннулуса.

Ссылка. Мотфотип имеет сходство со Стоматоцистой 20, Vorobyova et al., 1996 (Vorobyova et al., 1996), отличаясь по величие, размеру и форме шипов. Эти стоматоцисты и ранее встречались в Южном Байкале (Firsova et al., 2008), но обнаруженные нами в данном исследовании немного крупнее при этом воротничок немного меньше.

В результате анализа проб, отобранных в 2016 г. по всему Байкалу наблюдалось неравномерное распределение морфотипов стоматоцист. Так, самыми распространенными являются Стоматоциста 223 Firsova \& Likhjshway, 2006, которая встречается по всему Байкалу, чаще всего на станциях Южного и Среднего Байкала, и лишь на одной станции в Северном Байкале (ст. № 23, с. Байкальское-Турали). Большинство морфотипов распространены по всему Байкалу, это Стоматоцисты 156 Zeeb \& Smol, 1993, 223 Firsova \& Likhoshway, 2006,302 Firsova, 2006, 347 Firsova, 2006, 317 Firsova, 2006, 338 Firsova, 2006, 307 Firsova, 2006. Есть морфотипы, которые встречались в Южном и Северном Байкал и не были отмечены в Среднем, это - Стоматоцисты 189 Firsova \& Likhoshway, 2006 (ст. 2, 25), 314 Firsova \& Likhoshway, 2006 и новая Стоматоциста 450 Firsova \& Bessudova 2017 (ст. 3 , 19, 24). С другой стороны, стоматоцисты 451 Firsova \& Bessudova, 454 Firsova \& Bessudova и 262 Zeeb \& Smol, 1996 отмечены только в Северном Байкале. Интересно, что эти морфотипы имеют длинные шипы.

Все приведенные в статье морфотипы обнаружены в сентябре 2016 г., кроме Стоматоцисты 42 Duff \& Smol, 1991, отмеченной в мае-июне на станции ст. 17 (Чивыркуйский залив); в сентябре ни на одной из станций этот морфотип не встречался. Вероятно, вид формирующий этот морфотип стоматоцисты является весенним, и его развитие приурочено к более низким температурам.

\section{Выводы}

В результате анализа сезонных проб фитопланктона 2016 г., отобранных по всему Байкалу, подтверждены ранее опубликованные данные о максимальном обилии и разнообразии морфотипов стоматоцист в осенний период. В пробах, отобранных в сентябре, обнаружено 20 морфотипов стоматоцист. Больше половины из них (13) встречаются по всему Байкалу, лишь 5 морфотипов встречаются только в Южной части Байкала и три - в северной части озера. 
Firsova, A.D. et al. (2017). New data of chrysophycean.... Acta Biologica Sibirica, 2017, 3(4), 113-122

В исследованных нами пробах Стоматоциста 156 Zeeb \& Smol, 1993 была часто почти полностью покрыта чешуйками Chrysoshpaerella coronacircumspina, в результате чего мы считаем, что данная стоматоциста относится к этому виду хризофитовых. Аналогично мы считаем, что Стоматоциста 302 Firsova, 2006 принадлежит виду Spiniferomonas septispina. Стоматоцисты 156 Zeeb \& Smol, 1993, 262 Zeeb \& Smol, 1996 и 319 Brown \& Smol, 2001 в Байкале были отмечены впервые. Среди 20 обнаруженных морфотипов 5 описаны как новые для науки.

\section{Благодарности}

Работа выполнена в рамках темы бюджетного финансирования ФАНО № 0345-2016-0001 «Исследования эволюционных, экологических и молекулярно-биологических аспектов кремний-зависимых хромист как основных участников круговорота кремния в водных экосистемах» на приборах ЦКП «Электронная микроскопия», входящем в Объединенный ЦКП «Ультрамикроанализ» ЛИН СО РАН.

\section{References}

Bessudova, A.Yu., Firsova, A.D., Sorokovikova, L.M., Tomberg, I.V. (2016). Cheshuythatyie zolotistyie vodorosli basseynov nizhnego Eniseya i zalivov Karskogo moray s elementami autekologii. Irkutsk: Izd. Inst. Geografii (in Russian).

Cronberg, G., Sandgren, C.D. (1986). A Proposal For the development of standardized nomenclature and terminology for Chrysophycean statospores. In: Kristiansen J., Andersen R.A. (Eds.) Chrysophytes: aspects and problems. Cambridge: Cambridge University Press, 317-328.

Duff, K.E, Zeeb, B.A., Smol, J.P. (1995). Atlas of Chrysophycean stomatocysts. Dordrecht: Kluwer Academic Publishers.

Firsova, A.D., Kuzmina, A.E., Tomberg, I.V., Potemkina, T.G., Likhochway, Ye.V. (2008). Sezonnaya dinamica formirovaniya stomatocyst chrysophytovych vodorosley $v$ planktone Yuzhnogo Baikala. Izvestiya RAN. Seriya Biologitcheskaya, 5, 589-596 (in Russian).

Firsova, A.D., Likhoshway, Ye.V. (2006) Atlas chrysophycean cysts of Lake Baikal. Novosibirsk: Nauka (in Russian).

Hällfors, G., Hällfors, S. (1988). Records of chrysophytes with siliceous scales (Mallomonadaceae and Paraphysomonadaceae) from Finnish inland waters. Hydrobiologia, 161, 1-29.

Pla, S. (2001). Chrysophycean cysts from Pirenees. Berlin: J Cramer, 237.

Rybak, M., Rybak, I., Nicholls, K. (1991). Sedimentary chrysophycean cyst assemblages as paleoindicators in acid sensitive lakes. J. Paleolimnology, 5, 19-72.

Safronova, T.V, Voloshko, L.N. (2013). Silica-scaled chrysophytes in the waterbodies of protected areas of the NorthWest of Russia. Nova Hedwigia, 142, 097-115.

Scoble, J.M., Cavalier-Smith, T. (2014) Scale evolution in Paraphysomonadida (Chrysophyceae): Sequence phylogeny and revised taxonomy of Paraphysomonas, new genus Clathromonas, and 25 new species. European J. Protistology, 50, 551-592.

Škaloud, P., Kynčlová, A., Benada, O., Kofroňová, O., Škaloudová, M. (2012) Toward a revision of the genus Synura, section Petersenianae (Synurophyceae, Heterokontophyta): morphological characterization of six pseudocryptic species. Phycologia, 51, 303-329.

Škaloud, P., Škaloudová, M., Pichrtová, M., Němcová, Y., Kreidlová, J., Pusztai, M. (2013) www.chrysophytes.eu - a database on distribution and ecology of silica scaledchrysophytes in Europe. [Electronic resource] http://chrysophytes.eu/.

Tanichev, A.I., Bondarenko, N.A. (1995). Svobodnozhivushie zhgutikovyie. In: O.A. Timoshkin (Ed.) Atlas i opredelitel pelagobiontov Baikala s kratkimi ocherkami po ich ekologii. Novosibirsk: Nauka, 146-181 (in Russian).

Voloshko, L.N. (2016). Zolotistyie vodorosli (Chrysophyta) vodoyomov severo-zapada Rossii. Raznoobrazie stomatocyst. Botanicheskiyi Journal, 101 (11), 1257-1281 (in Russian).

Voloshko, L.N., Gavrilova, O.V., Gromov, B.V. (2002). Raznoobrazie Cyrysophyta (Paraphysomonadaceae, Mallomonadaceae, Synuraceae) v regione Ladozhskogo ozera. Algologia, 12 (2), 25-35 (in Russian).

Vorobyova, S.S., Bondarenko, N.A., Karpova, S.A., Pomazkina,G.V., Tanichev, A.I. (1992). K izucheniyu vidovogo sostava Chrysophyta ozera Baikal. Algologia, 2 (3), 68-72 (in Russian).

Vorobyova, S.S., Pomazkina, G.V., Baranova, E.Yu., Likhoshway, Ye.V., Sandgren, C.D. (1996). Chrysophycean cysts (stomatocysts) from Lake Baikal and Irkutsk Reservoir, Siberia. J. Paleolimnol, 15, 271-277.

Wilkinson, A.N., Zeeb, B.A., Smol J.P. (2001). Atlas of Chrysophycean Cysts. Dordrecht: Kluwer Academic Publishers.

\section{Citation:}

Firsova, A.D. Bessudova, A.Yu. Likhoshway, Ye.V. (2017). New data of chrysophycean stomatocysts from Lake Baikal. Acta Biologica Sibirica, 3 (4), 113-122.

Submitted: 11.07.2016. Accepted: 28.10.2017

cross ref http://dx.doi.org/10.14258/abs.v3i4.3637

(C) 2017 by the authors. Submitted for possible open access publication under the terms and conditions of the Creative Commons Attribution (CC BY) license (http://creativecommons.org/licenses/by/4.0/). 